\title{
Housing, management characteristics, and factors associated with lameness, hock lesion, and hygiene of lactating dairy cattle on Upper Midwest United States dairy farms using automatic milking systems
}

\author{
James A. Salfer, ${ }^{*}$ Justin M. Siewert, $\dagger$ and Marcia I. Endres $\dagger^{1}$ \\ *Regional Center, University of Minnesota Extension, St. Cloud 56301 \\ †Department of Animal Science, University of Minnesota, St. Paul 55108
}

\begin{abstract}
The objectives of this cross-sectional study were to describe housing and management practices on farms using automatic milking systems (AMS) in 2 states of the upper Midwest and to evaluate the association of various housing and management factors with 3 measures of animal welfare: prevalence of lameness, severe hock lesions, and dirty cows. Fifty-four farms were visited once to collect facility measurements and observations, interview the dairy producer, and score cows for locomotion, hock lesions, and hygiene. Median number of AMS units/farm was 2 (interquartile range $=1$; range $=1$ to 8 ). Factors concerning labor were the most commonly cited reason by dairy producers for making the transition to the AMS; additional commonly cited factors were an improvement in lifestyle and human health. Number of cows fetched per AMS, or manually brought to the AMS if not milked voluntarily, was 4.7 \pm 2.3 cows/AMS per day ( $8 \%$ of cows) for free traffic flow farms and $3.3 \pm 1.8$ cows/AMS per day $(5 \%$ of cows) for guided traffic flow farms. Cow resting surface was significantly associated with prevalence of lameness and severe lameness. Farms with sand-bedded freestalls $(17.2 \%)$ and bedded packs $(17.4 \%)$ had significantly lower lameness prevalence (score $\geq 3$ on a 1 to 5 scale, with $1=$ normal locomotion) than farms with mattress freestalls (30.5\%), waterbeds $(25.0 \%)$, and mattresses with access to pasture (22.6\%). Farms with mattresses and access to pasture had similar lameness prevalence to farms with waterbeds, but were lower than farms with mattresses only. A somewhat similar result was found for severe lameness prevalence (score $\geq 4$ on a 1 to 5 scale, with $1=$ normal locomotion); farms with sand-bedded freestalls $(2.8 \%)$, bedded packs $(0.0 \%)$, and mattress freestalls with access to pasture (1.5\%) had significantly lower prevalence than farms with
\end{abstract}

Received October 2, 2017.

Accepted April 27, 2018.

${ }^{1}$ Corresponding author: miendres@umn.edu mattresses $(7.1 \%)$ or waterbeds $(10.8 \%)$. Severe hock lesion prevalence (score $=3$ on a 1 to 3 scale, with 1 $=$ normal, $3=$ swelling) in herds with sand-bedded freestalls, waterbeds, and bedded packs were similar and significantly lower than the prevalence in mattressbased freestalls. Cows housed in sand-bedded freestalls had significantly lower prevalence of dirty cows (score $=3$ or 3.5 on a 1 to 5 scale, with $1=$ clean) than those housed on mattresses and waterbeds, and had significantly lower prevalence of severely dirty cows (score $=4,4.5$ or 5 on a 1 to 5 scale, with $1=$ clean) than all other housing systems except waterbeds, which was similar. Manure removal system (manual, automatic, or slatted floor) was significantly associated with prevalence of severely dirty cows; farms with manual scraping had lower prevalence of severely dirty cows than farms where alley scraping was practiced automatically or slatted floors were used. Dairy producers using AMS appeared to be successful with a variety of facility designs and management practices. Cow resting surface in AMS herds was associated with some animal health and welfare measurements.

Key words: automatic milking, lameness, robotic milking

\section{INTRODUCTION}

The first automatic milking systems (AMS) were installed in commercial dairy farms in the Netherlands in 1992 (de Koning and van de Vorst, 2002). In AMS, cows come voluntarily to a robotic milking station to be milked without human intervention, with the exception of a small percentage of cows that need to be fetched because they exceed maximum milking intervals as defined by the user. This is different from conventional milking systems, where cows are brought by humans to a milking parlor as a group to be milked typically 2 or 3 times a day. Similar to conventional milking systems, AMS have been used in various types of housing throughout the world, such as pasture-based (Lyons et al., 2013), freestall barns, and bedded pack barns (de 
Jong et al., 2003). However, management and specific housing characteristics could be different in AMS compared with conventional farms.

In recent years, a growing number of dairy farmers in North America have implemented AMS for a variety of reasons, including improved quality of life, issues associated with hired labor, and improved quality of management of the dairy herd (de Jong et al., 2003). Most of the research with AMS has been conducted in Europe (Klaas et al., 2003; Hogeveen et al., 2004; Bach et al., 2007) and more recently in Canada (King et al., 2016; Westin et al., 2016). Limited information exists about housing, management practices, and reasons for AMS installation on dairy farms in the United States. Based on field observations and a limited number of studies, both free (where cows have unrestricted access to the feeding area, lying area, and AMS unit) and guided flow (where cows must visit areas of the barn in sequence, such as from lying area to the AMS unit to the feeding area, using a combination of preselection and one-way gates) cow traffic patterns have been successfully used in AMS. The housing design with AMS might be different to conventional milking barns, and hence worth researching.

Measures of animal welfare, such as prevalence of lameness, hock lesions, and dirty cows, have not been extensively investigated in AMS farms in the United States. In addition, limited research has been conducted to evaluate the association of these measurements with various housing and farm management factors in AMS. Borderas et al. (2008) found lameness prevalence to be associated with lower milking frequency in AMS. Lameness is a very costly disease, ranging in cost from about $\$ 120$ to over $\$ 300$ per case, depending on the type of lesion (Cha et al., 2010). A recent study in Canada (King et al., 2016) assessed lameness in AMS herds and found lameness and severe lameness prevalence of 26 and $2.2 \%$, respectively.

The objective of our cross-sectional study was to describe housing and management practices on farms using AMS in 2 states in the upper Midwest. In addition, we investigated associations between some housing and management characteristics and the prevalence of some measures of animal welfare, namely lameness, severe hock lesion, and dirty cows, which had not been previously studied in this region of the United States.

\section{MATERIALS AND METHODS}

\section{Farms and Data Collection}

Fifty-four dairy farms in the Midwest (Minnesota and Wisconsin) using AMS were visited between June and September 2012 to collect on farm data for this observational study. At the time of study enrollment, it was estimated (based on AMS dealer information) that these farms represented the majority $(>85 \%)$ of farms using AMS in these 2 states. Farms in the current study had installed Lely Astronaut (Lely Industries N.V., Maassluis, the Netherlands) or DeLaval VMS (Delaval International AB., Tumba, Sweden) AMS.

During farm visits, data were recorded by research personnel on current barn design, including number of AMS units per farm and per pen, whether the barns were built new or retrofitted, number of freestalls per pen (when applicable), type of manure-removal system used for the barn alleys, cow resting surface, free or guided flow cow traffic, ventilation system, length (m) of the exit lane from the AMS and depth of open area (m) in front of the AMS entrance, the presence and location of a footbath, and barn lighting practices. Barn lighting practices were recorded to learn whether cows would have light at all times of day as they entered the AMS area or not, and whether lighting protocols were similar to conventional herds. In addition, milk production per cow $(\mathrm{kg} / \mathrm{d})$ was obtained from the AMS software at each farm (yearly average for year of visit, collected remotely).

Farm managers were interviewed in-person by research personnel during the farm visit to collect information on overall herd management practices, labor, adaptation of the cows to the AMS, fetching routine and number of cows fetched per day (average for the previous month), number of AMS calls per day (average for the previous month), and experience with equipment failures and repairs (average for the previous year). One question was about the reason for installing AMS and another was about perceived factors for success with AMS. The questionnaire had 43 open-ended or short answer questions (such as "please describe feeding management protocols" or "on average, how many cows do you fetch per AMS per day").

\section{Lameness Prevalence}

A minimum of $30 \%$ of cows in all pens as a representative sample of the herd (Endres et al., 2014) were scored for locomotion by a single trained observer using a 5-point scoring method (Flower and Weary, 2006), where $1=$ normal, $2=$ imperfect locomotion, $3=$ lame, and 4 and $5=$ severely lame. Cow identification was recorded by the observer to avoid scoring the same cow more than once; cows were scored by the observer as they walked in the freestall alleys for a minimum of 6 strides without impediment, and approximately every 3rd cow was scored. Locomotion score data were used 
to calculate a prevalence of lameness (percent of cows scoring $\geq 3$ ) and severe lameness (percent of cows scoring $\geq 4$ ) in each pen.

\section{Hock Lesion Prevalence}

A minimum of $30 \%$ of cows in all pens as a representative sample of the herd (Endres et al., 2014) were similarly scored by a single trained observer for the presence of a severe hock lesion, which was characterized by an open wound or swollen hock (swelling $\geq 2$ $\mathrm{cm})$. Presence of a severe lesion on 1 of the hocks was sufficient to classify a cow as having a lesion. Prevalence of hock lesion was calculated as the percent of cows scored with a severe lesion within each pen. During the protocol development and training for cow scoring methods it was concluded that scoring of less-severe lesions (i.e., hair loss) could not be consistently performed by the trained observer; therefore, only severe lesion prevalence was evaluated in the current study.

\section{Hygiene Assessment}

A minimum of $30 \%$ of cows in all pens as a representative sample of the herd (Endres et al., 2014) were similarly scored for hygiene by a single trained observer on a 5 -point scale, ranging from $1=$ clean to $5=$ extremely dirty (using 0.5 -point increments). Hygiene of the lower hind legs and udder were assessed, as these areas of the cow have been found to be highly associated with SCS (Reneau et al., 2005). Scores of the udder and the 2 hind legs were averaged to obtain a single score for each cow; therefore, a cow could score a $1,1.5,2,2.5,3,3.5,4,4.5$, or 5 . A cow with a score of 3 or 3.5 was categorized as dirty and a cow with a score of $4,4.5$, or 5 was categorized as severely dirty. The number of cows in each category within each pen was then used to calculate a prevalence of dirty and severely dirty cows for each pen.

\section{Statistical Analysis}

Descriptive statistics of the general farm parameters at the time of visit, including number of AMS units per farm and per pen, number of cows in the herd before and after AMS installation, number of freestalls per pen, milk production per cow, open area in front of the AMS entrance, length of the exit lane from the AMS, number of cows per full time equivalent (FTE) worker, number of cows fetched by traffic flow system per day (average for the previous month), the minimum and maximum concentrate allowances in the AMS milking station and percent of forage in the partial mixed ration, number of dealer calls per month (average for the previous month), and alley scraping protocols by type of manure removal system, were evaluated using the MEANS procedure (SAS 9.4; SAS Institute Inc., Cary, NC). Variable skewness was visually assessed. When data appeared normally distributed, mean \pm standard deviation were reported; when data appeared non-normally distributed, median, interquartile range (IQR), and range were reported.

The FREQ procedure (SAS 9.4) was used to describe the frequency of AMS by manufacturer, type of housing before AMS installation, reason for installing AMS, new or retrofitted facility for the AMS, manure-removal system, cow resting surface type, type of cow traffic flow, ventilation system, presence of cow grooming brushes, lighting and footbath protocols, cows' adaptation to the AMS, type of concentrate fed in the AMS, feed bunk management, and perceived factors for success with AMS.

The MIXED procedure (SAS 9.4) with the LSMEANS and PDIFF options was used to evaluate the associations between each outcome of interest, namely lameness, severe lameness, hock lesion, dirty cow and severely dirty cow prevalence (in 5 separate mixed model analyses) with cow resting surface, traffic flow system, manure-removal system, whether the AMS was installed in a new or retrofitted barn, depth of the area $(m)$ in front of the AMS entrance area, length (m) of the protected exit lane from the AMS, and use of a footbath, as these were considered to be potential factors influencing the outcomes. Farm was included as a random effect in each model. A univariable analysis was first conducted with each variable and outcome of interest. Factors with a $P<0.3$ were included in the initial multivariable models. Backward elimination was used to remove nonsignificant factors until all remaining factors had a $P<0.05$ in the final models. Model assumptions were evaluated using residual plots.

\section{RESULTS AND DISCUSSION}

\section{Descriptive Analysis}

Farm Characteristics. Farms represented a variety of management styles and housing systems. Median number of AMS units/farm was $2(\mathrm{IQR}=1$; range $=$ 1 to 8 ). Farms had a median of 1 AMS unit/pen (IQR $=1$; range $=1$ to 3 ) and a median of 60 freestalls $/$ pen $(\mathrm{IQR}=49.8$; range $=42$ to 165$)$. Approximately $30 \%$ of the farms had DeLaval VMS and $70 \%$ had Lely Astronaut AMS. Milk production averaged $33.2 \pm 5.3$ $\mathrm{kg} / \mathrm{cow}$ per day. Farms had a median herd size of 100 milking cows $(\mathrm{IQR}=80$; range $=42$ to 340$)$ before the 
installation of an AMS. After the AMS installation, median herd size was 120 milking cows $(\mathrm{IQR}=60$; range $=60$ to 480 cows). Most farms had Holsteins, except 1 farm with Jerseys. The herd size in the current study was slightly larger than the herds surveyed by de Jong et al. (2003), where farms averaged 110 milking cows and 1.9 AMS/farm. This increase in herd size may be reflective of recent dairy industry trends for larger average herd sizes across the United States. In addition, recent economic models (Salfer et al., 2017) suggested that AMS economic feasibility has improved over older models (Rotz et al., 2003), probably because of better AMS performance and higher milking labor costs. Other noneconomic factors, such as the availability of labor or the desire for an improvement in lifestyle, may be increasingly pertinent in making the decision between AMS and conventional milking systems.

Type of Housing Prior to AMS Installation. Prior to installing AMS, $57 \%$ of the farms housed their cows in a tiestall or stanchion barn, $37 \%$ housed them in a freestall barn, and $6 \%$ did not report or used another type of housing system. Additionally, $43 \%$ of the farms were milking in a parlor before installation of the AMS, with the remainder milking in a tiestall or stanchion barn.

Type of Housing After AMS Installation. In transitioning to using AMS, $56 \%$ of the farms in the current study built new facilities and $37 \%$ retrofitted existing facilities to install the AMS; $7 \%$ did a combination of retrofitting and building a new facility. Of the 49 herds with freestall barns, $55 \%$ had freestalls with mattresses, $31 \%$ used sand bedding, and $14 \%$ had waterbeds. The remaining 5 herds had bedded packs. Manure removal was performed using automatic alley scrapers in $46 \%$ of the herds, manual scraping in $26 \%$, automatic scraping and slats in different pens in $4 \%$, slatted floors without robotic scrapers in $11 \%$, slatted floors with robotic scrapers in $7 \%$, and bedded packs in $6 \%$.

Seventy-four percent of the farms used free flow cow traffic, $24 \%$ guided flow cow traffic, and $2 \%$ both free flow and guided flow cow traffic in different barns. In all guided flow systems cows walked through sort gates as they left a certain area of the barn. The sort gates directed the cow into the milking pen or away from the milking pen depending on milking permission parameters determined by the manager. There were also one-way gates preventing the cow from returning to certain areas of the barn. On 55\% of guided flow barns, the gate sorted cows as they left the freestall or resting area either to the AMS or to the feed bunk area (commonly called "milk first system") depending on the milking permission settings. Fifteen percent of the farms had a milk first system, but cows had access to a computerized grain feeder after leaving the AMS and before entering the feed bunk area. Another $30 \%$ of the farms had the sort gate as cows left the feed bunk area, where they were guided to the AMS or freestall area depending on milking permission (commonly called "feed first system"). After leaving the AMS, half of the feed first system farms (or 15\% total) guided cows back to the feed bunk area before being allowed to enter the freestall area. The other half of the feed first systems used the gate to guide cows directly back to the freestall or resting area.

Barns on $65 \%$ of the farms were naturally ventilated, $22 \%$ had tunnel ventilation, and $13 \%$ were cross-ventilated. Rotating cow grooming brushes were used on $83 \%$ of the farms. Median open area in front of the AMS station was $36.2 \mathrm{~m}^{2}$ (IQR $=40$; range $=11.1$ to 187.3), and the median depth of this area extending out from the AMS station was $6.1 \mathrm{~m}(\mathrm{IQR}=2.74$; range $=$ 2.1 to 12.2). The median length of the exit lane from the AMS station was $2.4 \mathrm{~m}(\mathrm{IQR}=3.2$; range $=0.3$ to $8.5 \mathrm{~m}$ ). Exit length is of interest, as it may have an effect on how rapidly cows exit the AMS following milking, with longer exit lanes suggested to reduce the risk of a cow's exit from the AMS being blocked by another cow standing idle at the exit of the AMS (Jacobs et al., 2012).

Lighting. Facility lighting practices varied considerably from farm to farm. Nineteen percent of the farms left the lights on in the barn and AMS area $24 \mathrm{~h} / \mathrm{d}$. Eighty-three percent provided light in the AMS area 24 $\mathrm{h} / \mathrm{d}$, whereas the remaining $17 \%$ of the farms had no lighting in the AMS for at least part of the night. Forty percent of the farms had scheduled long-day lighting in the pen (described as between 16 and $18 \mathrm{~h}$ of light/d). Thirty-two percent of the farms provided more than 18 $\mathrm{h}$ of light/d, whereas the remaining $28 \%$ of the farms provided less than $16 \mathrm{~h}$ of light/d. In conventional systems, long-day lighting has been shown to have a positive association with milk yield (Dahl et al., 1997), and some of the AMS farms were following this lighting protocol.

Footbath Use and Location. A footbath was used on $70 \%$ of the farms. Nineteen percent of the farms that did not use footbaths used a spray-on hoof health product in the AMS or freestall area. Of the farms using footbaths, $38 \%$ used them once/week or less, $35 \%$ used them 2 to 3 times/week, and $27 \%$ used them $>3$ times/week. Twenty-four farms provided the location of the footbath; $71 \%$ placed the footbath at the exit of the AMS, $4 \%$ placed it at the end of the barn, and $25 \%$ placed the footbath somewhere else in the pen. Some farms did not want to install the footbath near 
the AMS unit because of the concern that it may affect visits to the AMS milking station. There is a need for more research on what is the best location within the barn for installing footbaths in AMS farms.

Labor on AMS Farms. Fifty-one farms provided information on labor efficiency, a major factor for farms choosing to adopt robotic milking. Farms in the current study managed their herd with a median of 96 $(\mathrm{IQR}=69 ;$ range $=28$ to 180$)$ cows $/ \mathrm{FTE} ; 5$ farms had $>150$ cows/FTE. In comparison, Caraviello et al. (2006) reported that conventional dairy farms (average herd size of 613 cows) had 84 cows/FTE. Bewley et al. (2001) reported that smaller Wisconsin herds (up to about 300 cows/herd) using parallel or herringbone parlors had 40 to 45 cows/FTE. It appears that AMS farms compare favorably with larger farms from a labor efficiency standpoint.

Adaptation of Cows to the AMS. Adaptation of the cows to be milked voluntarily by the AMS is a concern for people considering the installation of AMS. From the responses of 37 of the farms in the study, $38 \%$ reported having $\leq 1 \%$ of cows failing to adapt to the system, $49 \%$ had $>1 \%$ but $\leq 5 \%$ adapt, $3 \%$ had $>5$ and $<10 \%$ fail to adapt, and $11 \%$ had $\geq 10 \%$ fail to adapt. An additional 4 farms continued to milk cows that did not adapt to the AMS in a conventional milking parlor. Rodenburg (2002) reported Ontario farms experienced 0 to 3 additional involuntary culls annually (mean herd size of 94 cows) due to udder conformation issues, particularly with rear teats placed too close together or too far back on the udder.

Fetching Cows to Be Milked. Although most cows visit the AMS voluntarily, farm workers need to routinely bring cows to the AMS when they fail to visit the AMS milking station on time as defined by the permission settings for milking interval on each farm. These cows are flagged by the AMS software in a daily attention list. Data on fetching was available for 41 of the farms, of which $66 \%$ had free flow systems and $39 \%$ had guided flow systems (2 farms used both free and guided flow traffic in different barns). We did not compare the 2 types of traffic flow. Seventy-eight percent of the farms fetched cows to the AMS 2 times/d, $17 \%$ fetched cows 3 times $/ \mathrm{d}$, and $5 \%$ fetched cows $>3$ times/d. Free flow farms reported fetching $4.7 \pm 2.3$ cows/AMS per day or approximately $8 \%$ of the cows. Farms using guided flow traffic pattern reported fetching $3.3 \pm 1.8$ cows/AMS per day or approximately $5 \%$ of the cows. In contrast, Rodenburg and House (2007) reported that farms fetched $16.2 \%$ of the cows in free traffic systems and $8.5 \%$ in guided traffic flow systems.

Feeding Management and Nutrition. Field observations indicated that feeding management was very important for the success of AMS; therefore, we wanted to describe feeding practices on AMS farms in this region of the United States. Of the 41 farms that provided this information, $95 \%$ fed pellets in the AMS milking station, $2.5 \%$ fed both a meal and pellets, and $2.5 \%$ (which was a certified organic farm) fed soybeans and oats. Five percent of the farms that fed pellets supplemented fresh cows with pellets and meal. Some farms had previously fed a meal in the AMS but had since transitioned to a pellet. Access to a palatable concentrate feed in the AMS milking station is critical for the success of AMS farms, as the opportunity to receive concentrate feed is a greater motivation for cows to visit the AMS milking station than the opportunity to be milked (Prescott et al., 1998). Rodenburg et al. (2004) reported that feeding harder pellets less prone to crumbling was associated with more frequent cow visits to the AMS and reduced need for fetching compared with feeding softer pellets. Pelleted feeds have also been shown to be preferred over meals by heifers in shortterm experiments (Spörndly and Åsberg, 2006).

Thirty-nine farms provided information about the amount of concentrate feed offered through the AMS milking station. The mean amount allowed per cow per day in the AMS was $1.9 \pm 1.1 \mathrm{~kg}$ for guided flow and $6.6 \pm 2.5 \mathrm{~kg}$ for free flow traffic farms. The concentrate feeding amounts in the free flow traffic farms in the current study were greater than those suggested by Bach and Cabrera (2017), who recommended limiting concentrate allowance to less than 3 to $4 \mathrm{~kg} / \mathrm{d}$ with no more than $1.5 \mathrm{~kg}$ fed per milking.

Feed push-up protocols varied considerably among farms. Of 43 farms for which data were available, $35 \%$ had an automatic feed pusher, $21 \%$ used a feed bunk system where feed push-ups were not necessary (either "J" bunks or "H" bunks where cows had access to both sides of the bunk), and $44 \%$ pushed up feed manually. For those farms manually pushing up feed, $47 \%$ of them pushed up feed 1 to 3 times/d and $53 \%$ pushed up feed 4 to 12 times/d. Most of the automatic systems pushed up feed every hour or every other hour, resulting in 12 to 24 feed push-ups per day on those farms. King et al. (2016) found a positive association between lying time and the number of feed push-ups per day in AMS herds in Canada. However, DeVries et al. (2003) and Bach et al. (2008) found no association between feed push-up frequency and measures of milk production efficiency in AMS herds.

Perceived Factors for Success. We asked 41 of the farms what they believed to be some of the most important factors for success when managing cows in an AMS. Responses varied considerably, but feeding and nutrition, computer use, and cow management 
were reported by 51,41 , and $37 \%$ of the farms, respectively. Other commonly reported factors included spending time watching cows, keeping on top of AMS maintenance, barn layout and design, as well as patience and the ability to be adaptable. These responses were similar to those reported by de Koning and van de Vorst (2002) as keys to successfully implementing and managing an AMS dairy farm.

Factors Influencing Decision to Install AMS. The top 3 categories of reasons for transitioning to milking with an AMS were ability to milk more cows with less labor, improved lifestyle, and human health (less risk of repetitive motion injury from the milking process). Labor was the most prevalent factor, with $60 \%$ of the farms listing it as 1 of their top 3 reasons, and $43 \%$ as their number 1 reason for making the transition. Improvement in lifestyle and free time was the second most prevalent reason, with $55 \%$ of the farms reporting it as 1 of their top 3 reasons, followed by an improvement in human health for $28 \%$ of the farms. We also found that $23 \%$ of the farms needed to invest in new facilities and concluded that AMS was the newest technology available and likely the future of the milking process. In addition, $18 \%$ of the farms stated they desired to have access to more information and technology in managing their cows. Additional commonly reported factors in making the decision to install AMS included (in percent of farms reporting as 1 of their top factors) improvement in cow health (15\%), expected increase in milk yield or milk quality (15\%), consistency for the cows (13\%), and individual quarter milking $(10 \%)$. These findings are comparable to Hogeveen et al. (2004), where reduced heavy labor (56\%), increased flexibility (35\%), and less labor available (30\%) were frequently reported reasons for the decision to install AMS. Other reasons for implementing an AMS that were commonly reported in both the current study and the study by Hogeveen et al. (2004) included health of the cow, the need for investment in a milking system, and the potential for increased milk yield. Interestingly, whereas $30 \%$ of the farmers reported being able to milk more than twice per day as a reason in the survey by Hogeveen et al. (2004), only $5 \%$ of the farmers in the current study listed this reason as 1 of their top 3 motivations for installing the AMS.

\section{Mixed Model Analysis}

Lameness Prevalence. Data from 52 farms (93 pens; 3,273 cows) were included in the analysis of lameness prevalence. Based on initial univariable analysis results, resting surface type $(P=0.002)$, manureremoval system $(P=0.059)$, whether the farm built a new barn or retrofitted an existing facility $(P=0.219)$, and depth $(\mathrm{m})$ of the area at the AMS entrance $(P=$ 0.128 ) were included in the initial multivariable model for their association with lameness prevalence. Only resting surface was retained in the final model $(P=$ 0.002 ). Lameness prevalence was $17.2 \pm 2.6 \%$ (LSM $\pm \mathrm{SE}$ ) for sand-bedded farms, $22.6 \pm 4.3 \%$ for farms with mattresses and 24-h pasture access (during the grazing season, otherwise housed in freestall barn), $17.4 \pm 5.6 \%$ for bedded pack systems, $25.0 \pm 3.7 \%$ for farms with waterbeds, and $30.5 \pm 1.9 \%$ for farms with mattresses. Lameness prevalence was greater for herds with mattresses than herds with bedded packs $(P=$ $0.033)$ and sand-bedded stalls $(P<0.001)$, and tended to be greater than mattresses with pasture access $(P=$ 0.091). Herds with waterbeds tended to have greater lameness prevalence than sand-bedded systems $(P=$ 0.092 ) and were similar to mattress with pasture access systems $(P=0.677)$.

For severe lameness prevalence, resting surface type $(P=0.001)$, manure-removal system $(P=0.112)$, cow traffic flow $(P=0.138)$, whether a footbath was used $(P=0.214)$, depth of the area in front of the AMS entrance $(P=0.155)$, and length of the exit lane from the AMS $(P=0.026)$ were included in the initial multivariable model. Resting surface and length of the exit lane remained in the final model $(P<0.05)$. Similar associations were found for severe lameness as compared with lameness prevalence; herds with sand, bedded packs, and mattresses with pasture access had a prevalence of $2.8 \pm 1.3,0.0 \pm 0.3$, and $1.5 \pm 0.5 \%$, respectively, which was lower than mattresses and waterbeds, at $7.1 \pm 1.0$ and $10.8 \pm 1.8 \%$, respectively $(P<0.05)$. Farms with waterbeds tended $(P=0.085)$ to have greater severe lameness prevalence than those with mattresses. Length $(\mathrm{m})$ of the exit lane from the AMS was negatively associated with severe lameness prevalence $(P=0.031$; estimate $=-0.007)$.

Previous research in conventionally milked freestall barns in these 2 states (Espejo et al., 2006; Cook, 2003) also found that the prevalence of lameness in herds with deep beds was significantly lower than herds with mattresses; the barn designs in the current study were not very different from conventional barns. Overall, the prevalence of lameness and severe lameness in the current study was higher relative to that found by Westin et al. (2016) in Canadian AMS dairy farms, where mean lameness and severe lameness prevalence was 15 and $4 \%$, respectively. However, depending on resting surface type, results of the current study were more similar to those of King et al. (2016) in Canadian AMS herds, where lameness and severe lameness prevalence were 26 and $2.2 \%$, respectively. 
Hock Lesion Prevalence. Data from 52 farms (93 pens; 3,249 cows) were included in the analysis of hock lesions. Resting surface type $(P<0.001)$, manure-removal system $(P=0.008)$, cow traffic flow $(P=0.294)$, and length $(\mathrm{m})$ of the exit lane from the AMS $(P=0.293)$ met the criteria for inclusion in the initial multivariable model. Resting surface type was retained in the final model $(P=0.002)$. Farms with sand, waterbeds, and bedded packs had severe hock lesion prevalence of $3.3 \pm 2.2,8.0 \pm 3.3$, and $1.9 \pm 4.9 \%$, respectively. These were lower $(P<0.05)$ than the hock lesion prevalence in herds with mattresses (16.2 $\pm 1.7 \%)$. The combined mattress and pasture system had a hock lesion prevalence of $13.8 \pm 3.9 \%$, which was greater $(P=0.025)$ than the sand-bedded freestalls, tended to be greater $(P=0.067)$ than bedded pack systems, but was similar to the waterbeds $(P=0.261)$. These results are similar to the findings of Fulwider et al. (2007), where conventional farms with rubber-filled mattresses had greater hock lesion prevalence than farms with sand bedding or waterbeds.

Hygiene. Resting surface type $(P<0.004)$, manureremoval system $(P<0.017)$, and traffic flow type $(P<$ 0.236 ) were included in the initial multivariable models for assessing the association of housing factors with prevalence of dirty and severely dirty cows. Backward elimination removed traffic flow from both models and manure-removal system from the dirty cow prevalence model. Resting surface type was retained in both final models $(P<0.03)$ and manure-removal system was also retained in the severely dirty cow prevalence $(P=$ 0.011) final model.

Prevalence of dirty cows was similar $(P>0.05)$ for farms with mattresses, waterbeds, bedded packs, and mattresses with pasture access. Farms with sandbedded freestalls tended to have $(P=0.095)$ a lower prevalence $(39.0 \pm 6.5 \%)$ of dirty cows than those with mattresses and pasture access $(59.4 \pm 10.1 \%)$, and had lower prevalence of dirty cows compared with farms with mattresses $(66.6 \pm 4.7 ; P=0.001)$ and waterbeds $(76.2 \pm 9.2 ; P=0.002)$.

Similar findings were obtained for prevalence of severely dirty cows. Farms with mattresses, waterbeds, and mattresses with pasture access had similar $(P>$ $0.05)$ severely dirty cow prevalence of $18.6 \pm 2.6,18.6$ \pm 5.2 , and $25.0 \pm 5.9 \%$, respectively. Farms with sandbedded freestalls had a lower prevalence $(8.4 \pm 3.9 \%)$ than mattresses $(P=0.034)$ and mattress with pasture access $(P=0.024)$, but were similar to waterbeds $(P=$ $0.126)$. These findings contradict those of Fulwider et al. (2007), where cows housed on sand were dirtier than those on mattresses or waterbeds.
Prevalence of severely dirty cows in manually scraped systems $(12.6 \pm 3.4 \%)$ was lower than both automatically scraped $(22.4 \pm 3.2 \% ; P=0.025)$ and slatted floor pens $(29.1 \pm 4.3 \%$; $P=0.003)$, which were similar to each other $(P=0.155)$. Farms with automatically scraped pens had a median of 12 scrapings/d (IQR $=6.4$; range $=1$ to 24 ) compared with the manually scraped pens which had a median of 2 scrapings/d $(\mathrm{IQR}=0$; range $=1$ to 3$)$. The worse hygiene scores of farms with automatically scraped barns might be attributed to cows walking through the deeper slurry of manure being pushed by the alley scraper, causing them to be dirtier. In contrast, DeVries et al. (2012) found increased frequency of alley scraping to be associated with improved hygiene scores. Due to a limited number of pens with slatted floors, slatted floor barns with and without an automatic alley scraping system were not separated in the analysis for the current study. Magnusson et al. (2008) found that slatted floor pens scraped with an automatic scraper compared with slatted floor with no scraping had 27 and $37 \%$ lower prevalence of dirty udders and teats, respectively.

Keeping cows clean is an important factor for success in AMS herds. Dohmen et al. (2010) showed that the annual average herd SCC in AMS herds was positively associated with the proportion of cows with dirty teats before milking and the proportion of cows with dirty legs. In addition, the annual average percentage of new cows with high SCC was positively associated with the proportion of cows with dirty teats before milking. At the cow level, hygiene scores of the udder, thighs, and legs were positively associated with SCC.

\section{CONCLUSIONS}

Farms were using AMS in a variety of facility designs in 2 states in the Upper Midwest, with many aspects of housing design found to be similar to conventional freestall barns with milking parlors. Both free flow and guided flow systems appeared to have been implemented successfully and did not differ in terms of animal welfare measurements assessed in this study. Cow resting surface was associated with lameness prevalence, severe hock lesion prevalence, and prevalence of dirty and severely dirty cows, as it has been previously observed in studies with conventional freestall farms. Manure-removal system was associated with prevalence of severely dirty cows. It is suggested that aspects of facility design and management practices that minimize prevalence of lameness, hock lesions, and dirty cows will help AMS be more successful, and should be taken into consideration when installing new AMS or improv- 
ing the facilities and management of farms currently using AMS.

\section{ACKNOWLEDGMENTS}

We thank all the dairy producers who participated in the study. In addition we thank Luis Espejo (St. Augustine, FL) for help with statistical analysis and Lucas Salfer (Dassel, MN) for collection of on-farm observations, cow scores, and producer questionnaire responses. We also thank David W. Kammel (University of Wisconsin, Biological Systems Engineering Department, Madison, WI) for his input on housing data collection, help with enrollment of Wisconsin AMS farms, and reading the manuscript draft. Justin Siewert was partially supported by a Department of Animal Science Fellowship (University of Minnesota) and the John Brandt Memorial Fund Scholarship (Land O'Lakes Inc., St. Paul, MN). This project was partially supported by Hatch Funds from the USDA National Institute of Food and Agriculture (Washington, DC).

\section{REFERENCES}

Bach, A., and V. Cabrera. 2017. Robotic milking: Feeding strategies and economic returns. J. Dairy Sci. 100:7720-7728. https://doi .org/10.3168/jds.2016-11694.

Bach, A., M. Dinarés, M. Devant, and X. Carré. 2007. Associations between lameness and production, feeding and milking attendance of Holstein cows milked with an automatic milking system. J. Dairy Res. 74:40-46. https://doi.org/10.1017/S0022029906002184.

Bach, A., N. Vallis, A. Solans, and T. Torrent. 2008. Associations between non dietary factors and dairy herd performance. J. Dairy Sci. 91:3259-3267. https://doi.org/10.3168/jds.2008-1030.

Bewley, J., R. W. Palmer, and D. B. Jackson-Smith. 2001. Modeling milk production and labor efficiency in modernized Wisconsin dairy herds. J. Dairy Sci. 84:705-716.

Borderas, T. F., A. Fournier, J. Rushen, and A. M. B. de Passillé. 2008. Effect of lameness on dairy cows' visits to automatic milking systems. Can. J. Anim. Sci. 93:427-433. https://doi.org/10.4141/ CJAS07014.

Caraviello, D. Z., K. A. Weigel, P. M. Fricke, M. C. Wiltbank, M. J. Florent, N. B. Cook, K. V. Nordlund, N. R. Zwald, and C. L. Rawson. 2006. Survey of management practices on reproductive performance of dairy cattle on large US commercial farms. J. Dairy Sci. 89:4723-4735. https://doi.org/10.3168/jds.S0022 $-0302(06) 72522-\mathrm{X}$

Cha, E., J. A. Hertl, D. Bar, and Y. T. Groehn. 2010. The cost of different types of lameness in dairy cows calculated by dynamic programing. Prev. Vet. Med. 97:1-8. https://doi.org/10.1016/j prevetmed.2010.07.011.

Cook, N. B. 2003. Prevalence of lameness among dairy cattle in Wisconsin as a function of housing type and stall surface. J. Am. Vet. Med. Assoc. 223:1324-1328.

Dahl, G. E., T. H. Elasser, A. V. Capuco, R. A. Erdman, and R. R. Peters. 1997. Effects of a long daily photoperiod on milk yield and circulating concentrations of insulin-like growth factor-I. J. Dairy Sci. 80:2784-2789. https://doi.org/10.3168/jds.S0022 -0302(97)76241-6.

de Jong, W., A. Finnema, and D. J. Reinemann. 2003. Survey of management practices of farms using automatic milking systems in North America. Accessed Jul. 27, 2017. http://milkquality .wisc.edu/wp-content/uploads/2011/09/survey-of-practices-using -automatic-in-na.pdf.

de Koning, K., and Y. van de Vorst. 2002. Automatic milking-changes and chances. Proceedings of the British Mastitis Conference Brockworth. Page 68-80. Accessed Sep. 22, 2017. http://citeseerx ist.psu.edu/viewdoc/summary?doi=10.1.1.583.7769.

DeVries, T. J., M. G. Aarnoudse, H. W. Barkema, K. E. Leslie, and M. A. G. von Keyserlingk. 2012. Associations of dairy cow behavior, barn hygiene, cow hygiene, and risk of elevated somatic cell count. J. Dairy Sci. 95:5730-5739. https://doi.org/10.3168/ jds.2012-5375.

DeVries, T. J., M. A. G. von Keyserlingk, and K. A. Beauchemin. 2003. Short communication: Diurnal feeding pattern of lactating dairy cows. J. Dairy Sci. 86:4079-4082. https://doi.org/10.3168/ jds.S0022-0302(03)74020-X.

Dohmen, W., F. Neijenhuis, and H. Hogeveen. 2010. Relationship between udder health and hygiene on farms with an automatic milking system. J. Dairy Sci. 93:4019-4033.

Endres, M. I., K. M. Lobeck-Luchterhand, L. A. Espejo, and C. B. Tucker. 2014. Evaluation of the sample needed to accurately estimate outcome-based measurements of dairy welfare on farm. J. Dairy Sci. 97:3523-3530. https://doi.org/10.3168/jds.2013-7464.

Espejo, L. A., M. I. Endres, and J. A. Salfer. 2006. Prevalence of lameness in high-producing Holstein cows housed in freestalls barns in Minnesota. J. Dairy Sci. 89:3052-3058.

Flower, F. C., and D. M. Weary. 2006. Effect of hoof pathologies on subjective assessment of dairy cow gait. J. Dairy Sci. 89:139-146. https://doi.org/10.3168/jds.S0022-0302(06)72077-X.

Fulwider, W. K., T. Grandin, D. J. Garrick, T. E. Engle, W. D. Lamm, N. L. Dalsted, and B. E. Rollin. 2007. Influence of free-stall base on tarsal joint lesions and hygine in dairy cows. J. Dairy Sci. 90:3559-3566. https://doi.org/10.3168/jds.2006-793.

Hogeveen, H., K. Heemskerk, and E. Mathijs. 2004. Motivations of Dutch farmers to invest in an automatic milking system or conventional milking parlour. Pages 56-61 in Automatic Milking: A Better Understanding. A. Meijering, H. Hogeveen and C. J. A. M. de Koning, ed. Wageningen Academic Publishers, Wageningen, the Netherlands.

Jacobs, J. A., K. Ananyeva, and J. M. Siegford. 2012. Dairy cow behavior affects the availability of an automatic milking system. J. Dairy Sci. 95:2186-2194. https://doi.org/10.3168/jds.2011-4749.

King, M. T., E. A. Pajor, S. J. LeBlanc, and T. J. DeVries. 2016. Associations of herd-level housing, management, and lameness prevalence with productivity and cow behavior in herds with automatic milking systems. J. Dairy Sci. 99:9069-9079. https://doi.org/10 .3168/jds.2016-11329.

Klaas, I. C., T. Rousing, C. Fossing, J. Hindhede, and J. T. Sorensen. 2003. Is lameness a welfare problem in dairy farms with automatic milking systems? Anim. Welf. 12:599-603.

Lyons, N. A., K. L. Kerrisk, and S. C. Garcia. 2013. Effect of preversus post milking supplementation on traffic and performance of cows milked in a pasture-based automatic milking system. J. Dairy Sci. 96:4397-4405. https://doi.org/10.3168/jds.2012-6431.

Magnusson, M., A. H. Herlin, and M. Ventorp. 2008. Short communication: Effect of alley floor cleanliness on free-stall and udder hygiene. J. Dairy Sci. 91:3927-3930. https://doi.org/10.3168/jds .2007-0652.

Prescott, N. B., T. T. Mottram, and A. J. F. Webster. 1998. Relative motivations of dairy cows to be milked or fed in a Y-maze and an automatic milking system. Appl. Anim. Behav. Sci. 57:23-33. https://doi.org/10.1016/S0168-1591(97)00112-3.

Reneau, J. K., A. J. Seykora, B. J. Heins, M. I. Endres, and R. J. Farnswolth. 2005. Association between hygiene scores and somatic cell scores in dairy cattle. J. Am. Vet. Med. Assoc. 227:1297-1301. https://doi.org/10.2460/javma.2005.227.1297.

Rodenburg, J. 2002. Robotic milkers: What, where . . . and how much!!?? Pages 1-18 in Proc. Ohio Dairy Management Conf., Columbus, OH. Ohio State University Extension, Columbus. 
Rodenburg, J., E. Focker, and K. Hand. 2004. Effect of the composition of concentrate fed in the milking box, on milking frequency and voluntary attendance in automatic milking systems. In Automatic Milking-A Better Understanding. A. Meijering, H. Hogeveen, and C. J. A. M. de Koning, ed. Wageningen Academic Publishers, Wageningen, the Netherlands.

Rodenburg, J., and H. K. House. 2007. Field observations on barn layout and design for robotic milking. In Proceedings of the Sixth International Dairy Housing Conference, Minneapolis, MN. ASABE Publication Number 701P0507e. https://doi.org/10.13031/ 2013.22804.

Rotz, C. A., C. U. Coiner, and K. J. Soder. 2003. Automatic milking systems, farm size, and milk production. J. Dairy Sci. 86:41674177. https://doi.org/10.3168/jds.S0022-0302(03)74032-6.
Salfer, J. A., K. Minegishi, W. Lazarus, E. Berning, and M. I. Endres. 2017. Finances and returns for robotic dairies. J. Dairy Sci. 100:7739-7749.

Spörndly, E., and T. Åsberg. 2006. Eating rate and preference of different concentrate components for cattle. J. Dairy Sci. 89:21882199. https://doi.org/10.3168/jds.S0022-0302(06)72289-5.

Westin, R., A. Vaughan, A. M. de Passillé, T. J. DeVries, E. A. Pajor, D. Pellerin, J. M. Siegford, A. Witaifi, E. Vasseur, and J. Rushen. 2016. Cow- and farm-level risk factors for lameness on dairy farms with automated milking systems. J. Dairy Sci. 99:3732-3743. https://doi.org/10.3168/jds.2015-10414. 